\title{
Practice and Opinion towards Disposal of Unused Medication in Kuwait
}

\author{
Eman A. Abahussain Douglas E. Ball Wandikayi C. Matowe \\ Department of Pharmacy Practice, Faculty of Pharmacy, Health Sciences Center, Kuwait University, Kuwait
}

\section{Key Words}

Medications wastage $\cdot$ Waste disposal $\cdot$ Expired

medications $\cdot$ Medicine supply management $\cdot$ Kuwait

\begin{abstract}
Objectives: The aim of this study was to measure the attitude and practice of Kuwaiti patients in Kuwait with regard to safe disposal of unwanted medicines. Subjects and Methods: Three-hundred patients or their family members waiting for prescriptions at public general hospitals in Kuwait completed a questionnaire soliciting their practice with regard to medication use and disposal, and their opinion of the best way to dispose of unwanted medicines. Results: Almost half of the respondents (45.4\%) obtained medicines on prescription more than 3 times a year and almost all had unwanted medicines in the home. Reasons for possessing unused medication were mostly due to a change of medication by the doctor (48.9\%), or self-discontinuation (25.8\%). Their most common method of disposal was to throw unwanted medicines in the trash (76.5\%) or flush them down the drain (11.2\%). Half (54.0\%) thought that a system of taking medicines to pharmacies for safe disposal would be favorable. Conclusion: The study indicates that the need for an appropriate method for disposal of unwanted medication exists in Kuwait. Hence, guidelines on safe disposal of unwanted medicines are required and an organized method of collecting unused medication needs to be introduced.
\end{abstract}

Copyright $\odot 2006$ S. Karger AG, Basel
(C) 2006 S. Karger AG, Basel

$1011-7571 / 06 / 0155-0352 \$ 23.50 / 0$

Fax +4161306 1234

E-Mail karger@karger.ch

www.karger.com
Accessible online at:

www.karger.com/mpp

\section{Introduction}

The disposal of unwanted medicines from households is becoming an increasing problem for local and national health and environmental authorities. Direct risks of unsafe disposal such as inappropriate medicine sharing, childhood poisonings and diversion of medicines to illicit use have been recognized for some time and environmental concerns are now receiving prominence. Newer and more sensitive analytical techniques make it possible to detect organic pharmaceutical compounds in groundwater and potable water even after treatment and purification $[1,2]$. In light of these findings, flushing medicines down the toilet or sink is now considered one of the least desirable methods of disposal since it may lead to persistence of discarded material in water supplies [3]. Survey reports from the USA and Canada have stated that 35\% and $46 \%$ of respondents reported that they disposed of unwanted medication down the drain, respectively $[4,5]$. Current regulations in the European Union and the USA require new medicines to be assessed for their environmental risk $[6,7]$, but existing medications are not covered by these regulations.

Although international guidance for corporations and governments exists on the disposal of healthcare waste [8], little information is available to the public and what is available is often inadequate and sometimes contradictory [9]. One method that has been used to provide an avenue for safe disposal of medication in homes is some sort of 'reverse distribution network'. In these systems, members of the public are requested to return unwanted

Dr. Eman Abahussain, Department of Pharmacy Practice

Faculty of Pharmacy, Health Sciences Center, University of Kuwait PO Box 24923, 13110 Safat (Kuwait)

Tel. +965 4986050 or 5312300 ext. 6050, Fax +965 5342807

E-Mail eman_abahussain@yahoo.com or eman_a@hsc.edu.kw 
medicines to local community pharmacies, which then arrange for pharmaceutical distributors or approved agents to collect and destroy them, e.g., the Return Unused Medicines project in Australia (www.returnmed. com.au, accessed 18 October 2005). In the United Kingdom, the value of unused medicines recovered in 'dump' (Dispose of Unwanted Medicines and Pills) campaigns has been estimated at $0.5-1.8 \%$ of local primary care drugs budgets [10] with an annual nationwide wastage cost of around GBP 37 million in 1996 [11]. This is likely to be an underestimate given that returns to pharmacies are likely to represent less than a third of all unused medicines [10]. In the United States, more than USD 1 billion worth of medicines prescribed for older patients go unused [12] each year and a 'dump' campaign in a Houston suburb collected USD 26,000 worth of solid oral dosage forms over a 6-month period [13], indicating that there are significant amounts of unused medicines kept in domestic environments.

One study that examined medication wastage in Saudi Arabia [14] found that over $80 \%$ of homes had five or more medicines present with an average of over 2 unused, expired or deteriorated products per household. It was estimated that the cost of medication wastage in Saudi Arabian homes was USD 10 per person per household with an annual national medication wastage of USD 150 million.

The extent of the problem of unused medication is not known in Kuwait. Given the health, environmental and economic consequences of unused medical products, the aim of this study was to measure the practice and attitude with regard to safe disposal of unused medicines by $\mathrm{Ku}-$ waiti patients receiving prescribed medicines at major public hospitals.

\section{Subjects and Methods}

An anonymous self-administered questionnaire in Arabic was developed and pretested with 50 eligible patients. The instrument was checked for readability, comprehension, question design and length. As a result of pretesting, some open-ended questions were converted to close-ended responses. The questionnaire informed respondents about the objective of the research and then elicited sociodemographic data including what medical conditions they were suffering from as well as their practice with regard to medication use and disposal, their opinion of the best way to dispose of unwanted medicines and an estimate of annual medicine expenditure. All the questions were close-ended questions, some with an option for the respondents to record their own opinion if the choices were not suitable. It was calculated that a sample size of 289 was needed for a precision in proportion of $5 \%$ at a significance level of 0.05 .

Disposal of Unused Medicines in Kuwait
The questionnaires were distributed to 300 Kuwaiti patients visiting the outpatient (ambulatory) pharmacies for prescription dispensing at five large public hospitals in Kuwait (Al-Adan, AlAmiri, Al-Sabah, Mubarak Al-Kabeer and Ibn-Sina Hospitals). The survey was conducted from April to July 2004. A pharmacist approached the patient and/or their carer, informed them of the survey and requested them to complete the questionnaire while waiting for their medications. For illiterate patients, a structured interview was carried out by the pharmacist based on the questionnaire. Permission to conduct the study was obtained from the Pharmaceutical Services Administration in the Ministry of Health. Patients were free to refuse to participate (the number declining to take part was not recorded). Data collection continued until 300 questionnaires had been completed. Simple proportions and tally were used in analyzing the data. In cases where respondents did not complete a question, these were treated as missing values and only complete answers were used for calculation of the results. The number of valid responses in such cases is stated in the text. The data were analyzed using the Statistical Package for Social Sciences (SPSS v.12, SPSS Inc.).

\section{Results}

Three hundred patients or their family members completed the questionnaire. The respondents' mean (SD) age was $37.9(12.2)$ years and $66 \%$ were male (table 1$)$. The majority were married (71\%), had postsecondary education (62\%) and had a monthly family income of less than KWD 1,000 (about USD 3,400). Respondents had an average of 2.3 current medical complaints of which cardiovascular disease (53.0\%), diabetes mellitus (35.9\%), allergy (29.6\%) and gastrointestinal complaints (22.6\%) were the most common (table 2).

Almost half (45.4\%) of the respondents reported that they obtained medicines on prescription from a health center more than 3 times a year, with a similar proportion claiming never to purchase medicines from private health facilities without a prescription (table 3). Sixteen percent reported getting medicines without prescription from a private pharmacy more than 3 times a year. The median estimated family cost of purchasing medicines from private pharmacies was KWD 25 (about USD 85).

Almost all respondents (95.7\%) reported that they had medicines in the home which they wished to dispose of. Solid oral dosage forms (66.2\%) and syrups (51.6\%) comprised the largest proportion of unwanted medicines followed by topical ointments/creams (35.2\%) and drops (32.4\%). Inhalers (10.5\%), injections (9.1\%) and syringes (3.8\%) were not commonly cited. No validation was performed to confirm these subjective self-reports. The most common method of disposal of unwanted medicines was to throw them in the trash $(76.5 \%)$ or flush them down 
Table 1. Background characteristics of the respondents $(n=300)$

\begin{tabular}{|c|c|c|c|}
\hline \multirow[t]{2}{*}{ Characteristic } & \multirow[t]{2}{*}{ Parameter } & \multicolumn{2}{|c|}{ Respondents } \\
\hline & & $\mathrm{n}$ & $\%$ \\
\hline \multirow[t]{5}{*}{ Source hospital } & Al-Adan & 48 & 16.0 \\
\hline & Al-Amiri & 80 & 26.7 \\
\hline & Al-Sabah & 58 & 19.3 \\
\hline & Ibn-Sina & 64 & 21.3 \\
\hline & Mubarak Al-Kabeer & 50 & 16.7 \\
\hline \multirow[t]{4}{*}{ Age, years } & $<25$ & 52 & 17.9 \\
\hline & $26-38$ & 107 & 36.9 \\
\hline & $39-51$ & 91 & 31.4 \\
\hline & $>51$ & 40 & 13.8 \\
\hline Gender & male & 186 & 66.4 \\
\hline \multirow[t]{4}{*}{ Marital status } & single & 64 & 22.0 \\
\hline & married & 206 & 70.8 \\
\hline & widowed & 4 & 1.4 \\
\hline & divorced & 17 & 5.8 \\
\hline \multirow[t]{4}{*}{ Schooling } & none & 16 & 5.3 \\
\hline & presecondary & 42 & 14.1 \\
\hline & secondary & 55 & 18.4 \\
\hline & postsecondary & 186 & 62.2 \\
\hline \multirow{4}{*}{$\begin{array}{l}\text { Monthly income } \\
\text { (KWD) }\end{array}$} & $<500$ & 67 & 22.6 \\
\hline & 500-999 & 118 & 39.9 \\
\hline & 1,000-1,499 & 55 & 18.6 \\
\hline & $>1,499$ & 56 & 18.9 \\
\hline \multirow{6}{*}{$\begin{array}{l}\text { Residential area } \\
\text { (suburb) }\end{array}$} & capital & 67 & 22.6 \\
\hline & Hawalli & 97 & 32.7 \\
\hline & Farwaniya & 35 & 11.8 \\
\hline & Ahmadi & 55 & 18.5 \\
\hline & Jahra & 18 & 6.1 \\
\hline & Mubarak Al-Kabeer & 25 & 8.4 \\
\hline
\end{tabular}

the toilet or sink (11.2\%) while some respondents (8.5\%) said they would give them to a friend. Other methods of disposal, e.g., returning them to a pharmacy, were cited by $11.9 \%$ of respondents.

A total of 264 respondents gave reasons why they would want to dispose of medicines in the home. These ranged from change or discontinuation of medication by the doctor (48.9\%), self-discontinuation of the medicine $(25.8 \%)$, having an excess of medication in the home $(30.3 \%)$, possessing expired medicines $(10.6 \%)$ or being prescribed and/or dispensed more medication than required (9.8\%). Seventy-four participants (28.1\%) were motivated to return medicines because somebody else might benefit from them while only $16.7 \%$ would return them for the purpose of 'proper disposal'.
Table 2. Current medical complaints amongst respondents

\begin{tabular}{ll}
\hline Condition & $\begin{array}{l}\text { Respondents, \% } \\
(\mathrm{n}=300)\end{array}$ \\
\hline Cardiovascular disease & 53.0 \\
Diabetes mellitus & 35.9 \\
Allergic conditions & 29.6 \\
Gastrointestinal and liver disease & 22.6 \\
Dermatological disease & 19.2 \\
Renal disease & 16.0 \\
Asthma & 16.0 \\
Rheumatic disease & 14.6 \\
Anemia & 11.1 \\
Other & 21.2 \\
\hline
\end{tabular}

Table 3. Respondents' frequency of obtaining medicines with and without a medical prescription in the past year

\begin{tabular}{llrr}
\hline & Frequency & \multicolumn{2}{c}{ Respondents } \\
\cline { 3 - 4 } & & $\mathrm{n}$ & $\%$ \\
\hline Medicines on & never & 19 & 6.4 \\
prescription & $1-3$ times & 69 & 23.4 \\
& $>3$ times & 134 & 45.4 \\
& can't recall & 73 & 24.7 \\
\hline Medicines without & never & 139 & 48.1 \\
prescription $^{1}$ & 1-3 times & 72 & 24.9 \\
& $>3$ times & 46 & 15.9 \\
& can't recall & 32 & 11.1 \\
\hline
\end{tabular}

${ }^{1}$ This reflects only purchases of medicines from private pharmacies since prescriptions are always required at government health facilities.

In response to what their opinion was on the best way for unused medicines to be collected for safe disposal ( $\mathrm{n}=287$ valid responses), 54\% thought that returning them to a local pharmacy would be appropriate, $21 \%$ thought there should be special collection containers at local shopping cooperatives while $15 \%$ preferred that medicines be collected from homes by the municipality and $3 \%$ offered other actions (7\% no opinion). Respondents were also asked to select ways of decreasing the amount of wasted medication. Most (77\%) felt the patient should be given the exact amount of medication required, while $40 \%$ thought that the public needed education on this topic. Sharing of unexpired medicines was accepted by $16 \% ; 14 \%$ felt that a consultation with a pharmacist could help to decide whether to discontinue treatment. A little over $10 \%$ of respondents felt that user fees or charg- 
es to obtain medicines (from government health facilities) would reduce wastage and $4 \%$ proposed other actions. No correlation or association was found between practice or opinion towards medication disposal and any of the demographic descriptor variables.

\section{Discussion}

This study examined the practice and opinion on unused medication disposal of 300 Kuwaiti patients or their family members at government hospitals in Kuwait. Kuwaiti citizens make up less than half of Kuwait's 2.5-million population, but are responsible for $60-70 \%$ of visits to primary and secondary health care institutions and therefore were the focus of this study. This restriction to a homogeneous Arabic-speaking population also allowed for easier questionnaire development and data collection since the expatriate, non-Kuwaiti population is very diverse in culture and language. Sourcing the subjects from the major public referral hospitals in Kuwait provided a wide cross section of the community. However, since most respondents had a monthly income less than KWD 1,000 , they would appear to be largely low-wage earners. A likely reason for this is that higher earners are more likely to use private clinics and hospitals. The large proportion of married respondents probably reflects that single persons are more likely to be young and therefore less likely to suffer from many of the chronic illnesses managed at hospital ambulatory clinics. Indeed, the majority of respondents suffered from chronic illness, especially cardiovascular disease and diabetes mellitus, common medical conditions in Kuwait's population. However, the fact that the patients were sourced from hospitals may mean that they are sicker than patients who receive their continuation medication from local polyclinics. It must be recognized that this study focused on Kuwaiti citizens. Non-Kuwaitis make up around $60 \%$ of the population of Kuwait and their habits in disposal of unwanted medication will also need to be investigated as part of a comprehensive plan to address this issue.

In Kuwait, Government health facilities provide free health care to the population under a compulsory health insurance scheme (for noncitizens) and government subsidies. Private health care facilities and retail pharmacies are mostly used by patients not satisfied with the national health system or who wish to obtain medicines (or brands of medicines) not available within the public health system. Most medicines for chronic diseases can be obtained from private pharmacies without a prescrip- tion. This structure of the health sector and the practice of public pharmacies to dispense 2 months of chronic medication at a time help explain the observation that about half of respondents obtained medicines on prescription more than 3 times a year with a similar proportion reporting to never obtain medication without prescription. Purchasing medicines without prescription from a private pharmacy can add to the load of unused or unwanted medicines in the home. About $16 \%$ of respondents said that they obtained medicines in this way, but this is likely to be an underestimate for the population, given that the respondents were sampled from a government health institution. Limitations of patient recall prevented a more accurate assessment of medication-seeking behavior and health expenditures in this study, but this should be examined further in future work.

Almost all respondents claimed to have unwanted medicines in the home. Given that these patients seem to represent lower wage earners who might be more likely to retain medicines for future use, the total unwanted medicine burden in the patient population of Kuwait is likely to be substantial. Three quarters of patients reported that they discarded unwanted medicines in the trash, with disposal down the drain, to friends (by sharing) and returning them to pharmacies each reported by around $10 \%$ of respondents. Where no organized collection system exists, disposal of medication in domestic garbage destined for landfill is accepted as more environmentally friendly than flushing them down the drains $[3,9]$. The disposal habits of these Kuwaiti patients are therefore 'better' than those reported for 500 United States households where $54 \%$ threw unwanted medication in the trash, 35\% flushed them down the toilet or sink and $1 \%$ returned them to a pharmacy [4], and a Canadian telephone survey which found that $46 \%$ used drainage systems, $31 \%$ trash and $17 \%$ returned unused medicines to the pharmacy [5].

This should however not give rise to complacency, since disposal in domestic trash is still only a measure of last resort [9] given that the risks of household healthcare waste disposed of by landfill have not been fully assessed [15]. The recommended method of disposal of most pharmaceuticals is incineration [8], which requires some initial organized method of collection and sorting. In many developed countries, some form of reverse distribution system or occasional 'dump' campaigns have been successful in collecting substantial volumes and values of unused or expired medicines for proper disposal [10, 11, 13]. A similar system could be introduced in Kuwait, with collection bins at local public and/or private pharmacies 
or health facilities in which members of the public could place unwanted medicines. Suitable measures would need to be in place to ensure the security of the returned medication to prevent diversion of narcotic and psychotropic drugs to illicit use [16] in keeping with international conventions [9]. Involvement of the local Kuwait Pharmaceutical Association would be essential and public education, e.g., through the mass media, would be crucial for the campaign to be successful given that only $12 \%$ of the patients in this survey had returned medicines to a pharmacy in spite of half responding that this would be an acceptable method.

Other methods of collection suggested by respondents included having special containers at local cooperative supermarkets and arranging for special collections by the municipality. The former would need special measures to prevent diversion of expired medicines or those of abuse potential [16]. The latter would require some means of separating the medicines or other healthcare waste from normal household garbage, e.g., through the use of special colored collection bags, and could be costly to administer. One of the attractive points of reverse distribution through local pharmacies is that it is cost-efficient [13].

In this survey, $9 \%$ of patients said they disposed of unused medicines by sharing them with friends and $16 \%$ believed sharing of unexpired medication to be acceptable. It has been previously estimated that in Gulf countries, $20-30 \%$ of household members use medicines originally prescribed for other persons [14]. The lower figure in the current study may reflect that the question was asked in the context of medicine disposal rather than recording past medication taking habits. Sharing of medicines without medical advice may be dangerous, even if the medicine has not expired. An inappropriate medication may be used and it is not possible to guarantee the quality of the pharmaceutical product if it has been improperly stored. Unexpired, unused medication are considered unsuitable for drug donations according to World Health Organization guidelines [17], although the reverse distribution system in France does involve separation of medicines in intact containers and suitable packaging for charitable use [18]. Raising the profile of pharmacists in Kuwait as health professionals who can advise on reuse and/or appropriate disposal of medication in the home was identified by the respondents as one way of reducing medication wastage in this study.

Three quarters of survey participants felt that medication wastage could be reduced by prescribing the exact amount of medicine needed. This suggests that they are receiving excessive amounts from the health system. Pre- scribing controls, e.g., formularies or clinical guidelines and dispensing restrictions could be useful in this regard. One study in the USA found elderly patients received over $120 \%$ of the amount of medication actually needed, with resultant increased health care costs [19]. It is reasonable to suspect that overprescription of medicines is present in the public health system of Kuwait where neither prescribers nor patients face disincentives for prescribing or receiving excess medicines, respectively. In fact, at public health facilities in Kuwait, most chronic disease patients receive 2 months' supply of medication per visit. Reducing this to a single month's supply could be a first step, although the implications of such a change on the supply management of medicines would need to be considered. Another option is the implementation of user fees or copayments for medicines, which was suggested by the respondents, although this measure is likely to be unpopular among Kuwaiti patients. Ideally a coordinated strategy to reduce overprescription of medicines together with measures to dispose of unused medication would be employed.

This study adds to what is known about disposal of waste medicines in Kuwait. One limitation is that it only considers the opinion and reported practice of Kuwaiti patients. While they are the greatest users of the health system, noncitizens also contribute to healthcare waste production and may follow less safe waste disposal practices. This needs to be investigated. Furthermore, the study relies on subjective reports by patients rather than direct observation of practice. Completing the questionnaire in a hospital environment in the presence of a pharmacist may have led respondents to provide answers which they thought were 'correct' rather than their actual perceptions or practice. Validation of such data is problematic.

This report indicates that there is a problem of unused medicines in households in Kuwait. Further research into the reasons for the retention of such medication, the quantities involved and the cost to individuals and the nation is necessary. In this regard, the practice and opinion of non-Kuwaiti citizens are also important. Although this study showed that patients appear to be generally following appropriate disposal methods, there are no official guidelines on disposal of domestic healthcare waste in Kuwait with which to encourage them to continue in this manner. Development of these guidelines and the introduction of a reverse distribution mechanism should be considered to support the efforts of the public and to reduce the environmental load which will result from continuing landfill of unwanted medicines and their packaging. The disposal of potentially mutagenic anti- 
cancer medication and biologicals also needs to be investigated as these can lead to serious adverse outcomes if discarded into household garbage.

\section{Conclusion}

The study indicates that the need for appropriate methods for disposal of unwanted medication in the home is a problem in Kuwait. Hence, guidelines on safe disposal of unwanted medicines are required and an organized method of collecting unused medication needs to be introduced.

\section{Acknowledgments}

The authors would like to acknowledge the efforts of the pharmacists who assisted with data collection.

\section{References}

1 Derksen JG, Rijs GB, Jongbloed RH: Diffuse pollution of surface water by pharmaceutical products. Water Sci Technol 2004;49:213221.

-2 Stackelberg PE, Furlong ET, Meyer MT, Zaugg SD, Henderson AK, Reissman DB: Persistence of pharmaceutical compounds and other organic wastewater contaminants in a conventional drinking-water-treatment plant. Sci Total Environ 2004;329:99-113.

-3 Daughton CG: Cradle-to-cradle stewardship of drugs for minimizing their environmental disposition while promoting human health. II. Drug disposal, waste reduction, and future directions. Environ Health Perspect 2003;111:775-785.

4 Kuspis DA, Krenzelok EP: What happens to expired medications? A survey of community medication disposal. Vet Hum Toxicol 1996;38:48-49.

5 Boivin M: The cost of medication waste. Can Pharm J, May 1997, pp 32-39.
6 Straub JO: Environmental risk assessment for new human pharmaceuticals in the European Union according to the draft guideline/ discussion paper of January 2001. Toxicol Lett 2002;135:231-237.

7 Bound JP, Voulvoulis N: Pharmaceuticals in the aquatic environment - a comparison of risk assessment strategies. Chemosphere 2004;56:1143-1155.

8 World Health Organization: Safe Management of Wastes from Health-Care Activities. Geneva, WHO, 1999.

9 Boehringer SK: What's the best way to dispose of medications? Pharmacist's Letter/ Prescriber's Letter 2004;20:200415.

10 Cromarty E, Downie G: Drug wastage - what is acceptable? Pharm J 2001;267:424.

11 Hawksworth GM, Wright DJ, Chrystyn H: A detailed analysis of the day to day unwanted medicinal products returned to community pharmacies for disposal. J Soc Admin Pharm 1996;4:215-222.

12 Morgan TM: The economic impact of wasted prescription medication in an outpatient population of older adults. J Fam Pract 2001; 50:779-781.

13 Garey KW, Johle ML, Behrmann K, Neuhauser MM: Economic consequences of unused medications in Houton, Texas. Ann Pharmacother 2004;38:1165-1168.
14 Abou-Auda HS: An economic assessment of the extent of medication use and wastage among families in Saudi Arabia and Arabian Gulf Countries. Clin Ther 2003;25:12761292.

15 Slack RJ, Gronow JR, Voulvoulis N: Household hazardous waste in municipal landfills: contaminants in leachate. Sci Total Environ 2005;337:119-137.

16 Baker R, Moss P, Upton D, Pankhania J: Investigation of systems to prevent diversion of opiate drugs in general practice in the UK. Qual Saf Health Care 2004;13:21-25.

17 World Health Organization: Guidelines for Drug Donations. Geneva, WHO, 1999.

18 MacArthur D: Any old drugs? Two schemes for the disposal of unwanted medicines in Europe. Pharm J 2000;264:223-224.

19 Stroupe KT, Murray MD, Stump TE, Callahan CM: Association between medication supplies and healthcare costs in older adults from an urban healthcare system. J Am Geriatr Soc $2000 ; 48: 760-768$. 